NBSIR 74-396

\title{
SPECIFICATIOH AND MEASUREMENT OF FREQUENCY STABILITY
}

John H. Shoaf

Time and Frequency Division Institute for Basic Standards National Bureau of Standards Boulder, Colorado 80302

November 1974 



\section{NBSIR 74-396}

\section{SPECIFICATION AND MEASUREMENT OF FREQUENCY STABLLITY}

John H. Shoaf

Time and Frequency Division Institute for Basic Standards

National Bureau of Standards

Boulder, Colorado 80302

November 1974

The results of this report are not to be used for advertising or promotional purposes, or to indicate endorsement or disapproval of the product(s) by the National Bureau of Standards.

This report is, with minor revisions, a reprint of an unpublished NBS Report bearing the same title and author, issued September 7, 1971

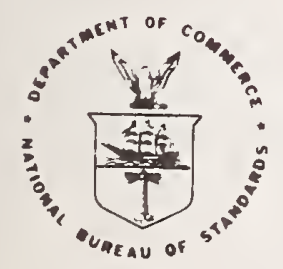

U.S. DEPARTMENT OF COMMERCE, Frederick B. Dent, Secretary NATIONAL BUREAU OF STANDARDS Richard W Roberts Director 

Contents

1. INTRODUCTION AND BACKGROUND . . . . . . . . . I 1

2. TERMINOLOGY FOR SPECIFICATION OF

FREQUENCY STABILITY . . . . . . . . . . . . . . 3

3. COMPARISON OF MEASUR EMENT TECHNIQUES . . . . . 6

4. OPERATIONAL SYSTEMS FOR MEASUREMENT

OF FREQUENCY STABILITY AT NBS . . . . . . . . . . . 9

5. MEASUREMENTS OF FREQUENCY ST ABILITY

AT MICROWAVE FREQUENCIES . . . . . . . . . . . . 19

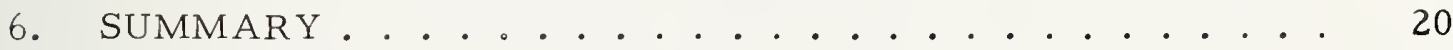

REFERENCES . . . . . . . . . . . . . . . . . . 21

APPENDIX A, Glossary of Symbols . . . . . . . . . . 22

APPENDIX B, A Sample Calculation of Script $\mathcal{L}$. . . . . . 24

APPENDIX C, A Sample Calculation of Allan Variance. . . . 25

APPENDIX D, Stability Measure Conversion Chart . . . . 27

APPENDIX E, General References and Selected Papers . . . 29

BIBLIOGR APHY . . . . . . . . . . . . . . . . . . . 32 
Figure 1 Frequency domain measurement of frequency stability ............ 10

Figure 2 Stepped-gain operational amplifier ....... 11

Figure 3 Low-noise amplifier .......... 12

Figure 4 Adjustable RC filter............ 13

Figure 5 Battery bias box............. 13

Figure 6 Plot of Script $\mathscr{L}(\mathrm{f})$ versus frequency $\mathrm{f} \ldots \ldots . . .14$

Figure 7 Time domain measurement of frequency stability................ 15

Figure 8 Plot of sigma versus tau ......... 16

Figure 9 Differential phase noise measurement . . . . 17

Figure 10 Adjustable phase shifter (5-MHz delay line) . . . 17 


\title{
SPECIFICATION AND MEASUREMENT \\ OF FREQUENCY STABILITY
}

\author{
John H. Shoaf \\ Atomic Frequency and Time Standards Section \\ National Bureau of Standards \\ Boulder, Colorado 80302 USA
}

\begin{abstract}
$\underline{\text { Abstract }}$
This report gives concise definitions for specifying frequency stability for measurements in the frequency domain and time domain. Standards of terminology and of measurement techniques are recommended. Measurement systems are described in adequate detail so that the apparatus may be duplicated. Proposed extension of the measurement systems through $12.4 \mathrm{GHz}$ is discussed.

Key Words: Allan variance, Frequency stability measurements, Measurement system description, Phase noise, Spectral density, Terminology standards.
\end{abstract}

\section{INTRODUCTION AND BACKGROUND}

At the beginning of FY 71 the Department of Defense Joint Services Calibration Coordinating Group (DoD/CCG), Ray Y. Bailey (Chairman), Newark Air Force Station, Newark, Ohio, initiated a proposal with the National Bureau of Standards (NBS) to write a survey paper pertaining to the specification and measurement of frequency stability. The project was under the jurisdiction of the DoD/CCG Time and Frequency Working Group. The members of this group are E. L. Kirkpatrick (Chairman), Aerospace Guidance and Metrology Center, 
Newark Air Force Station, Newark, Ohio; Lloyd H. Daniels, U. S. Army Metrology and Calibration Center, Redstone Arsenal, Alabama; and Peter Strucker, Metrology Engineering Center, Pomona, California. A widely-accepted, well-defined set of standards for the specification and measurement of frequency stability has been long overdue. A manuscript by the Institute of Electrical and Electronics Engineers Subcommittee on Frequency Stability appears to be the most comprehensive treatment of the subject to date. The manuscript [1], "Characterization of Frequency Stability" by Barnes et al., may be considered an authoritative paper on the subject; it has been used extensively in the preparation of this survey report.

This report gives recommended standards of terminology and measurement techniques in addition to comparison of other widely used contemporary measurement methods for determination of frequency stability. Operational systems for frequency stability measurement at the National Bureau of Standards are described in detail and extension of these systems to $12.4 \mathrm{GHz}$ is discussed. An extensive bibliography on frequency measurement is also included.

A comprehensive knowledge of the definitions and relations outlined below is necessary in order to understand the practical systems that are useful for measurement of frequency stability. It is the objective in this report to place the emphasis on details of useful working systems (apparatus) that may be duplicated by others in the field of frequency stability measurements. Uniformity of data presentatior is recommended to facilitate interpretation of stability specifications and to enable one to communicate and compare experimental results more readily.

Experience in the use of these measurement systems and these concepts will be the best teacher; this report is at most the teacher's assistant. 


\section{TERMINOLOGY FOR SPECIFICATION OF FREQUENCY STABILITY}

A general definition of frequency stability has been stated as "the degree to which a signal source (e.g., oscillator) produces the same value of frequency throughout a specified period of time." Measurement of stability can be accomplished in both the frequency domain (e.g., spectrum analysis) and the time domain (e.g., gated frequency counter). In the aforementioned manuscript [1] the authors chose to use two independent definitions, each related to different, useful methods of measurement. In addition to the following comments on definitions, a complete glossary of symbols for this paper is found in Appendix A.

The first definition of frequency stability (frequency domain) is the one-sided spectral density of the fractional frequency fluctuations, $y$, on a per hertz basis:

$$
\mathrm{S}_{\mathrm{y}}(\mathrm{f}) \equiv \text { spectral density of } \mathrm{y} \text {, }
$$

where $y$ represents the fractional frequency fluctuations, $y \equiv \delta \nu / \nu_{0}$. This measure of stability has the dimensions of inverse hertz. The spectral density of phase fluctuations is related by the identity, $S_{\delta \phi^{\prime}}(f)=S_{y}(f)\left[v_{0}^{2} / f^{2}\right]$.

The second definition of frequency stability (time domain) uses the type of sample variances called the Allan variance [2] of $y$ :

$$
\left\langle\sigma_{\mathrm{y}}^{2}(\mathrm{~N}, \mathrm{~T}, \tau)\right\rangle \equiv\left\langle\frac{1}{\mathrm{~N}-1} \sum_{\mathrm{n}=1}^{\mathrm{N}}\left(\overline{\mathrm{y}}_{\mathrm{n}}-\frac{1}{\mathrm{~N}} \sum_{\mathrm{k}=1}^{\mathrm{N}} \overline{\mathrm{y}}_{\mathrm{k}}\right)^{2}\right\rangle .
$$

This measure of stability is dimensionless. The bar over the y indicates that y has been averaged over a time interval $\tau$. The angular brackets indicate an average of the quantity over time. 
Further explanation of these definitions will be given later. A very complete discussion may be found in reference [1].

Frequency drift is defined as a systematic, typically linear increase or decrease of frequency with time. This is characterized as "aging rate" in crystal oscillators and is expressed in fractional parts per period of time. This report on frequency stability does not include a discussion of this so-called "linear drift."

In all known signal sources the output frequency is affected by noises of various types. The noises can be characterized by their frequency dependence. The random noises [1] include white thermal and shot noises $\left(f^{O}\right)$, flicker noise $\left(f^{-1}\right)$, and integrals of these noises.

It is the examination of these noise spectra with which we are concerned in the first definition of frequency stability given in eq (1). The fractional frequency fluctuation spectral density $S_{y}(f)$ is not to be confused with the radio frequency power spectral density $S_{\delta V}(\nu)$ which is not a good primary measure of frequency stability because of fluctuations in amplitude and for other reasons [1].

Since $S_{y}(f)$ of eq (1) is expressed in terms of the spectral density of phase fluctuations $S_{\delta \varnothing}(\mathrm{f})$, a convenient laboratory method of deter mining the phase noise would be useful. Phase noise spectral density plots are used for presenting frequency stability information in the frequency domain.

Script $\mathscr{L}(f)$ is a frequency domain measure of phase fluctuations (noise, instability, modulation) used at NBS. Script $\mathcal{L}(f)$ is defined as the ratio of the power in one phase noise sideband, referred to the input carrier frequency, on a per hertz of bandwidth spectral density basis, to the total signal power, at Fourier frequency $f$ from the carrier, per one device. 


$$
\mathscr{L}(\mathrm{f}) \equiv \frac{\text { Power density (one phase modulation sideband) }}{\text { Power (total signal) }} .
$$

For small $\delta \phi$,

$$
S_{\delta \phi}(f)=2 \mathcal{L}(f)
$$

A practical system for the measurement of $\mathcal{L}(f)$ or $S_{\delta \phi}(f)$ will be described in detail later.

In the time domain a useful determination of $\left\langle\sigma_{y}^{2}(N, T, \tau)\right\rangle$ of eq may be accomplished by utilization of the particular Allan variance [2] where specifically $\mathrm{N}=2$ and $\mathrm{T}=\tau$ such that

$$
\left.\sigma_{\mathrm{y}}^{2}(\tau) \equiv \sigma_{\mathrm{y}}^{2}(\mathrm{~N}=2, \mathrm{~T}=\tau, \tau)\right\rangle=\left\langle\frac{\left(\overline{\mathrm{y}}_{\mathrm{k}+1}-\overline{\mathrm{y}}_{\mathrm{k}}\right)^{2}}{2}\right\rangle .
$$

Plots of $\sigma$ versus $\tau$ on a log-log scale are commonly used as a presentation of frequency stability in the time domain. Convenient suitable systems and techniques used at NBS for obtaining time domain measurements of frequency stability will be discussed extensively later. 


\section{COMPARISON OF MEASUREMENT TECHNIQUES}

In this discussion we shall not concern ourselves with accuracy of a frequency. The primary concern shall be the measurement of fluctuations of frequency, i.e., instability or stability. It is sometimes convenient to refer to the instability as fractional frequency deviation.

The measurement of frequency fluctuations can be accomplished by one or more of several methods. In each method a precise (stable in time) reference is essential. In the case of measuring excellent sources an equally excellent reference source is needed.

The first method, direct counting of frequency by the use of counters, is straightforward. Here, successive values of frequency are read out directly and recorded. (The reference signal controls the counter gate.) Statistical analysis of the results are usually made. High resolution is not possible by this method when measuring the lower frequencies unless frequency multiplication is used. Two disadvantages of frequency multipliers are--one, a pair of specialized multiplier chains may be needed for each different carrier frequency range and, two, not only does the signal noise get multiplied but noise from the multiplier itself may be introduced.

A second method involves mixing the two frequencies and recording the beat. When the reference and signal frequencies are close in value, this requires determination of the fluctuations in very long beat periods. A quantitative measure of short-term frequency stability is not practical in this case. However, when a large offset frequency is introduced, the method is feasible for assessing stability when a readout device such as a period counter is used for observing fluctuations in the period of the beat. 
A somewhat similar method uses a phase sensitive detector for determining phase fluctuations between two signals which are approximately in phase quadrature (and hence must be at the same frequency). Short-term (or long-term) phase fluctuations may be recorded. In order to facilitate statistical analysis it is advantageous to drive an analog-to-digital converter and a counter with a printer. This method is related to the NBS system (time domain) which is described in detail in Section 4.

An interesting and fast method used for comparison of frequencies and also applicable to stability measurement (time domain) is the commercially available frequency error expander. Since frequency multiplication is used, the same disadvantages are present as in the first method where multipliers are employed. The principle of the error expander is that one of the signals is synthesized to a convenient offset frequency which is then mixed and multiplied in stages to obtain higher and higher resolution. Eventually, however, the region is reached where the noise becomes very great and frequency comparison is no longer possible.

It is noted that none of the above-mentioned conventional methods of measuring frequency stability utilize frequency domain techniques. As indicated previously, in order to have a comprehensive and sufficient measure of frequency stability it is preferred that the measurements involve both frequency and time domain techniques. This is recommended even though it is possible to compute time domain performance from frequency domain results and often conversely [1]. Appendix D contains a table which allows translation from one domain to the other. At least one manufacturer has made it convenient to determine frequency stability in the time domain with the results computed automatically [3], [4]. 
Others outside NBS have reported on excellent systems for frequency domain and for time domain measurements of frequency stability [5], $[6],[7],[8]$. Some of these resemble in principle the systems used at NBS. The techniques described by Van Duzer [5] and Meyer [6] best describe those used in the NBS systems.

Fortunately, frequency domain and time domain methods for measuring frequency stability require similar apparatus except that: to make measurements in the frequency domain you must have a frequency window (spectrum analyzer) following the detector; for the time domain you must have a time window (gated counter) following the detector. 


\section{OPERATIONAL SYSTEMS FOR MEASUREMENT OF FREQUENCY STABILITY AT NBS}

It was the introduction of good double-balanced mixers that permitted measurement of frequency stability by improved techniques. The double-balanced mixer, considered as a phase sensitive detector, makes possible meaningful frequency stability measurements of high-quality signal sources in both the frequency domain and the time domain. The results are quantitative and may be obtained from a measurement system which is reasonable in cost.

The frequency stability measurement systems described below have been used at NBS since 1967. The functional block diagrams in figures 1, 7, and 9 are referred to in the detailed descriptions of the particular systems. Certain commercial components utilized in the systems are referred to by brand name and model number. * Substitute components with similar specifications will give equivalent results.

* Certain commercial equipment, instruments, or materials are identified in this paper in order to adequately specify the experimental procedure. In no case does such identification imply recommendation or endorsement by the National Bureau of Standards, nor does it imply that the material or equipment identified is necessarily the best available for the purpose. 


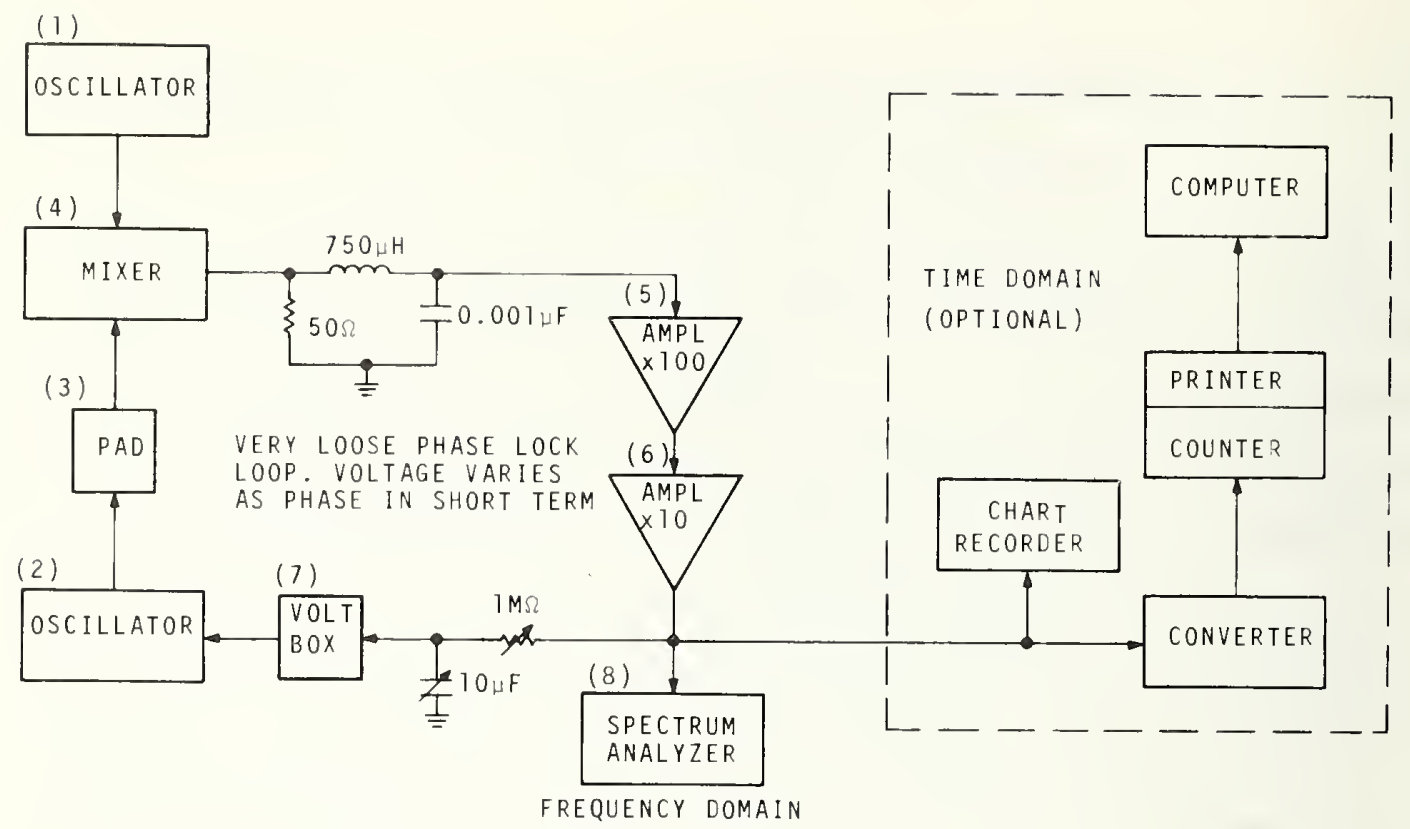

FIGURE 1: FREQUENCY DOMAIN MEASUREMENT OF FREQUEIICY STABILITY

(1) OSCILLATOR UNDER TEST

(2) REFERENCE OSCILLATOR OF HIGH SPECTRAL PURITY (VARACTOR TUNing)

(3) ADJUSTABLE ATTENUATOR (TYPICALLY 10dB)

(4) DOUBLE-BALANCED MIXER, HP MODEL 10514A (SCHOTTKY BARRIER DIODES)

(5) NBS LOW-NOISE dC AMPLIFIER (SEE FIGURE 3)

(6) OPERATIONAL AMPLIFIER, PHILBRICK MODEL P65AU OR P25AU (SEE FIGURE 2)

(7) BATTERY BIAS BOX (SEE FIGURE 5)

(8) SPECTRUM ANALYZER, QUAN-TECH MODEL 304

Figure 1 illustrates the measurement system typically used at NBS for frequency domain measurements. It should be noted that time domain data can also be obtained simultaneously, although usually this system is used only for frequency domain measurements. (For time domain measurements it is often more convenient to use a slightly modified measurement setup to be described later.' In this frequency domain setup the oscillator under test is fed into one side of a low-noise double-balanced mixer (HP Model 105 l4A), which utilizes Schottky barrier diodes. The reference oscillator is fed into the other side of the mixer through an attenuator, typically $10 \mathrm{~dB}$. The mixer acts as a phase sensitive detector so that when the two signals are idrntical in 
frequency and are in phase quadrature the output is approximately zero volts dc. When this output is sent back to the reference oscillator via the varactor tuning, phase lock is achieved. The phase lock loop contains proper termination at theoutput of the mixer followed by operational amplifiers with adjustable gain. The time constant of the loop may be adjusted as needed by varying the amplifier gain within the loop and by use of the RC filter indicated in the diagram. Finally, a battery bias box is included at the varactor input in order to operate in a suitably linear portion of the varactor's frequency versus voltage curve. A very loose phase lock loop is indicated inasmuch as the voltage varies as phase (in short term), and in this frequency domain measurement we are observing the small phase variations directly. Philbrick Model P65AU or P25AU operational amplifiers which are used are arranged in a circuit as shown in figure 2 for convenience of adjusting the gain and for self-contained

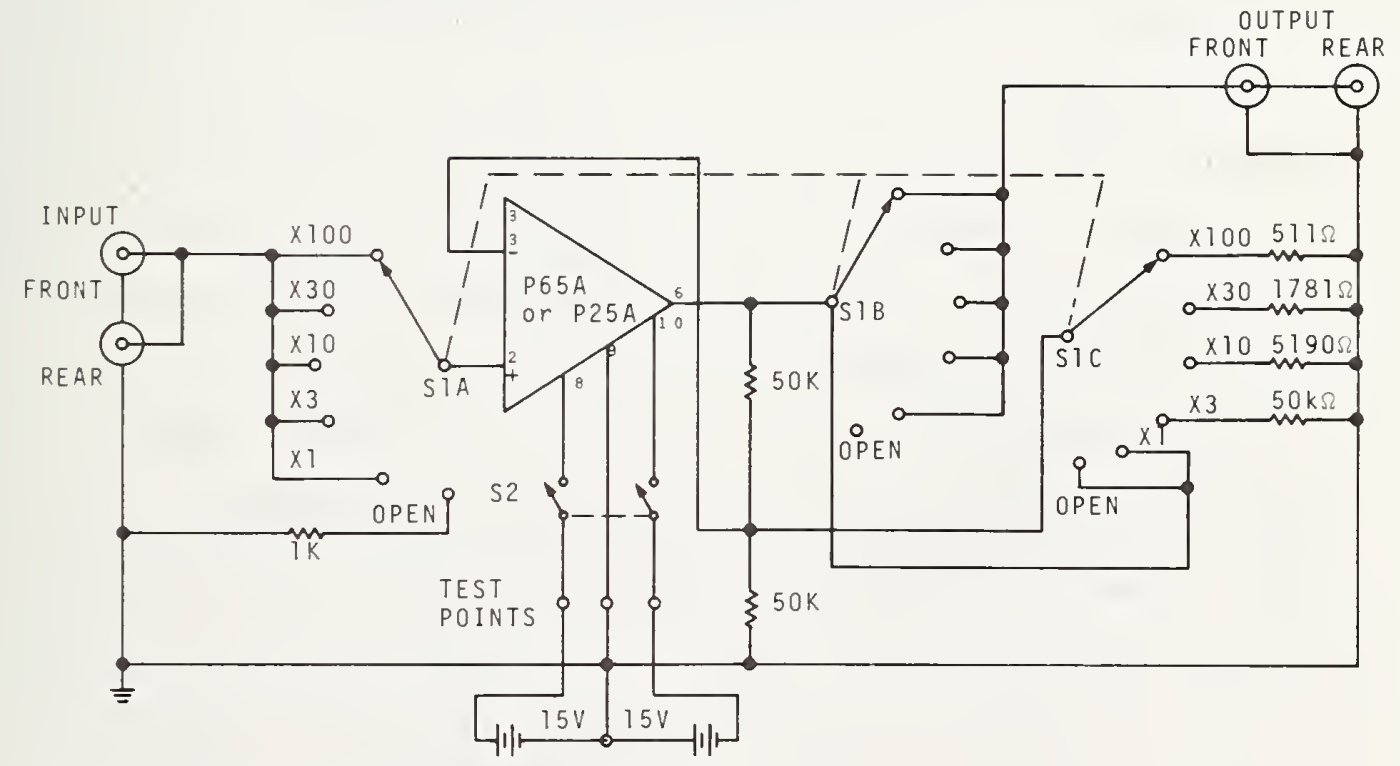

FIGURE 2: STEPPED-GAIN OPERATIONAL AMPLIFIER

battery supply voltage. Special NBS low-noise dc amplifiers used in certain precision measurements are shown in figure 3. At NBS we 


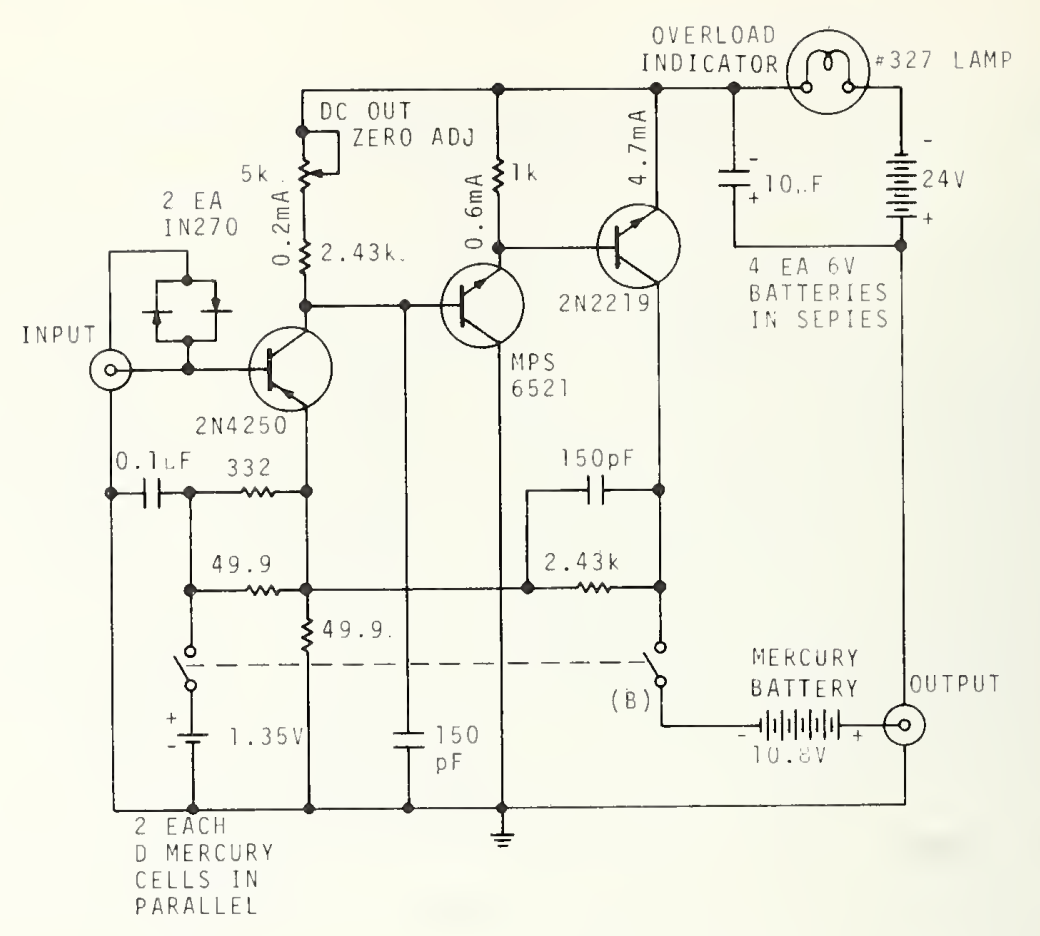

FIGURE 3: LOW WOISE AMPLIFIEP.

have arranged in a small chassis the adjustable RC or CR filters utilizing low-noise components, with rotary switches for various combinations of $\mathrm{R}$ and $\mathrm{C}$ (see fig. 4). The battery bias box is arranged with a vernier as shown in figure 5, facilitating fine frequency adjustments via the varactor frequency adjustment in one oscillator. A wave analyzer (Quan-Tech Model 304) is used to obtain the noise plot information relevant to stability (frequency domain). The phase noise sideband levels are read out in rms volts on the analyzer set to certain chosen values of frequency, f. This corresponds to measuring only those phase noise sidebands which are separated from the carrier by the various $f$ intervals chosen. Script $\mathscr{L}(f)$ may be calculated with the assumption that both sources contribute equally; however, if one source were the major contributor, then the noise of that source would be no worse than $3 \mathrm{~dB}$ greater than the value of $\mathscr{L}(\mathrm{f})$ so calculated. 


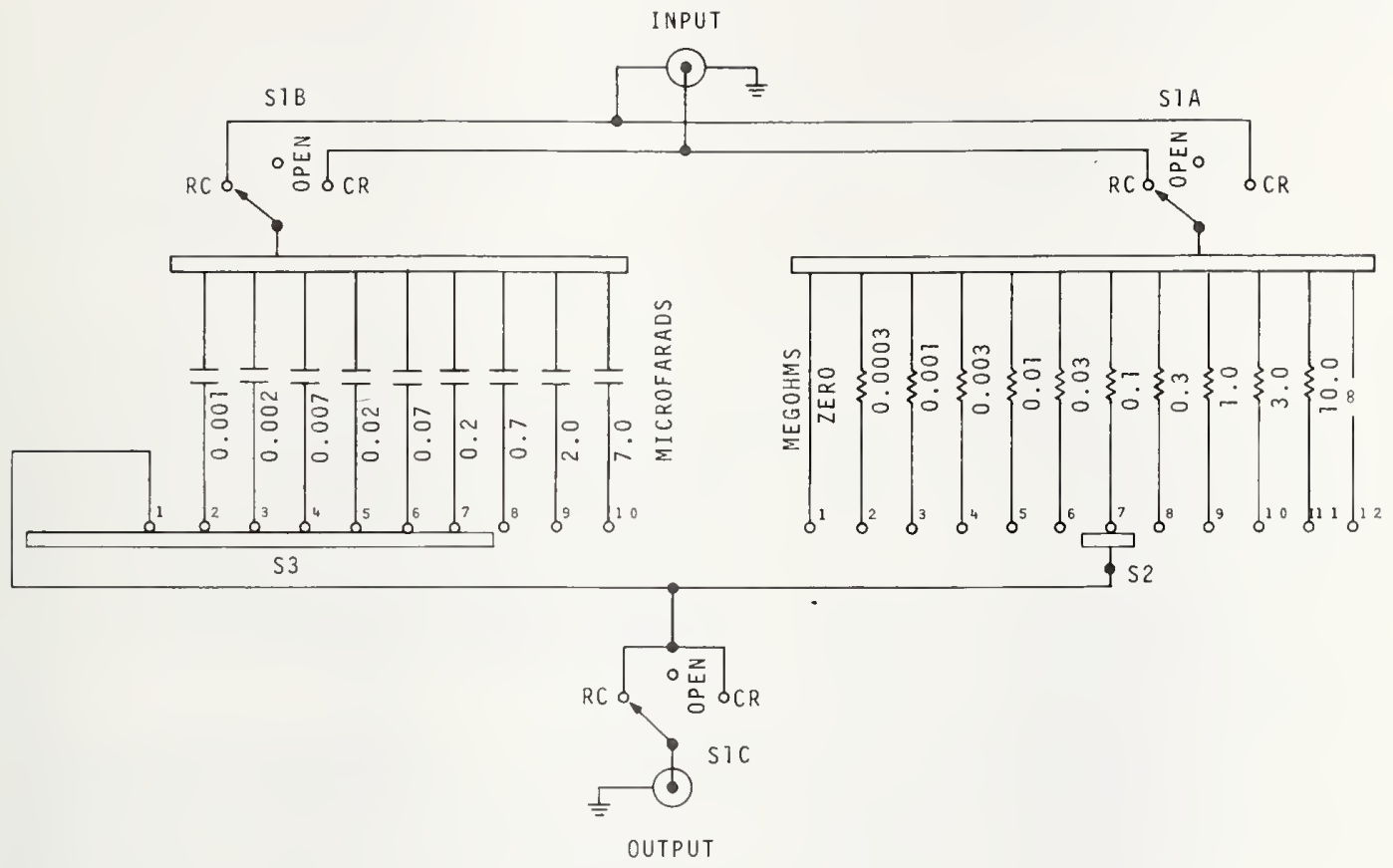

FIGURE 4: ADJUSTABLE RC FILTER

S1: FILTER MODE SWITCH (ROTARY, 3 WAFER)

S2: RESISTOR SWITCH (ROTARY, SHORTING TYPE)

S3: CAPACITOR SWITCH (ROTARY, PROGRESSIVE SHORTING)

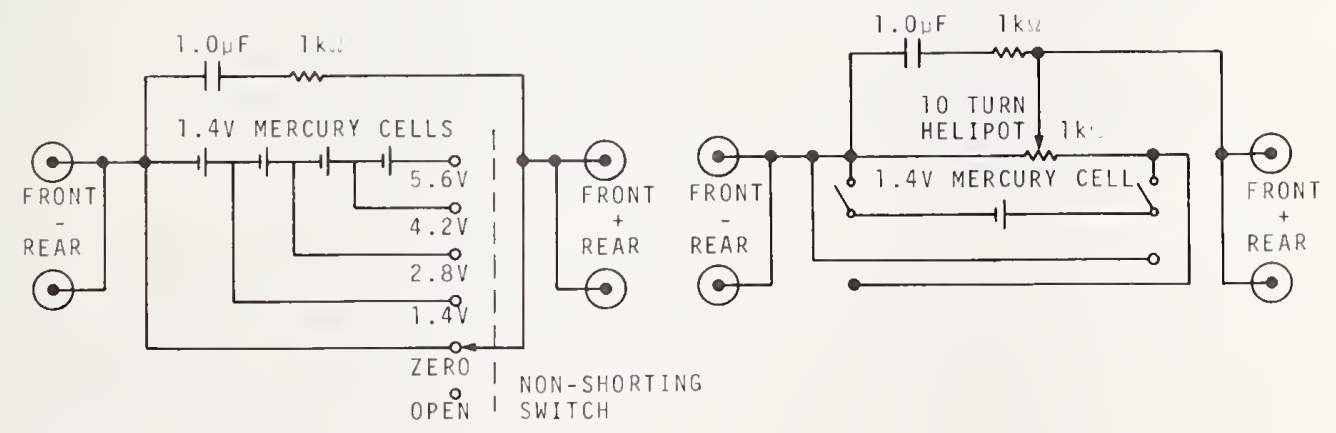

FIGURE 5: BATTERY BIAS BOX

THE UNITS ARE BUILT ON SEPARATE CHASSIS AND CONNECTED IN SERIES

TO FACILITATE FINE ADJUSTMENT BETWEEN STEP VOLTAGES 
A typical plot is shown in figure 6. A sample calculation may be found in Appendix B.

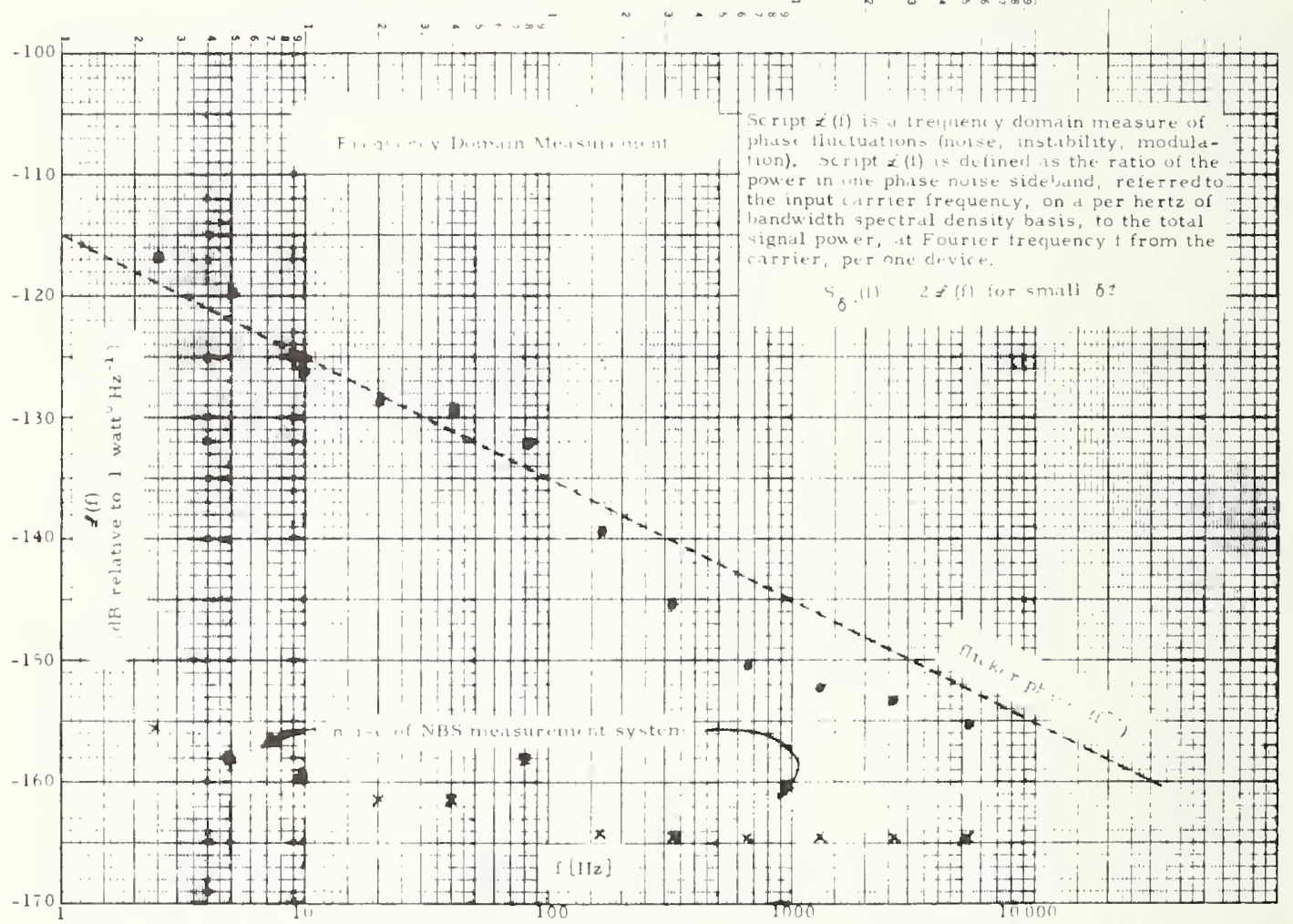

FIGURE 6 : SCRIFT $\mathcal{L}(f)$ VERSUS FREQULIICY $f$ 
In figure 7 a measurement system typically used at NBS for stability measurements in the time domain is shown. It will be noted
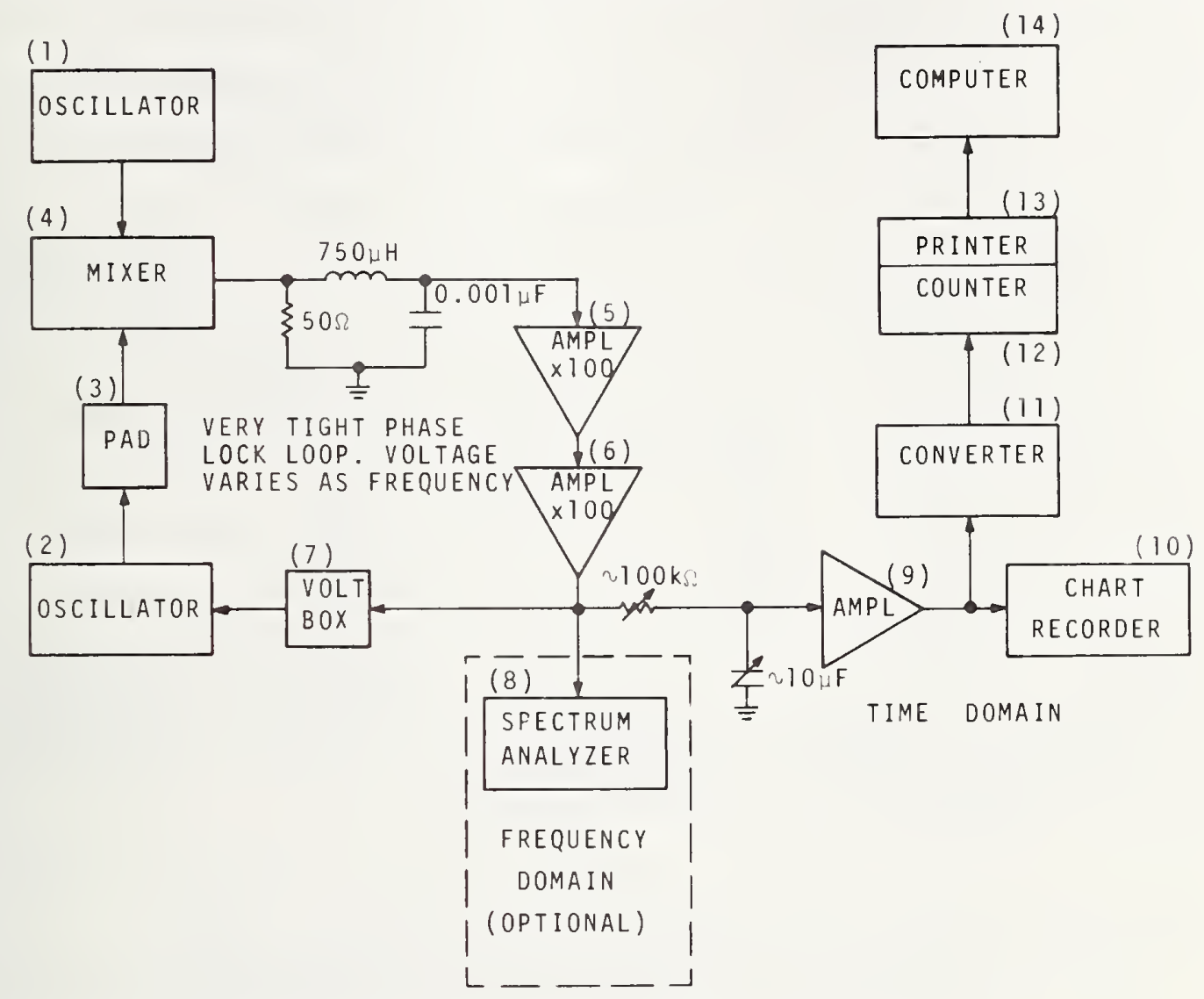

(14)

FIGURE 7: TIME DOMAIN IIEASUREMENT OF FREQUEICY STABILITY

ITEMS (1) THROUGH (8) SAME AS FIGURE 1

(9) OPERATIONAL AMPLIFIER, PHILBRICK P65AU OR P25AU

(10) STRIP CHART RECORDER FOR QUALITATIVE OBSERVATION (TYPE NOT SPECIFIED)

(11) VOLTAGE-TO-FREQUENCY CONVERTER, VIDAR MODEL 240

(12) FREQUENCY COUNTER WITH LOW DEAD TIME, HP MODEL 5325B

(13) DIGITAL RECORDER WITH FAST RECORDING'SPEED, HP MODEL $5050 B$ (INHIBIT TIME COMPATIBLE WITH COUNTER DEAD TIME)

(14) COMPUTER (OPTIONAL METHOD OF DATA ANALYSIS)

that the principle of operation is similar to that used in the frequency domain measurement wherein the reference oscillator is locked to the test oscillator. However, for the time domain measurement we use a very tight phase lock loop and the correction voltage at the oscillator varies as frequency. This is a very convenient setup for observing fre quency fluctuations in longer term. However, with the time constant appropriately adjusted and the means for taking sufficiently fast samples 
the system is readily used for short term measurements, as well as the longer term measurements, in the time domain. For qualitative observations any suitable oscilloscope or strip chart recorder may be used. For quantitative measurements the system at NBS utilizes a voltage-to-frequency converter (Vidar Model 240), a counter (HP Model 5325B), and printer (HP Model 5050B Digital Recorder) capable of recording rapid samples of data with very short dead time. The data are analyzed typically by computer via a program designed to compute the appropriate Allan variance [1], [2]. In our computer program it automatically plots on microfilm $\log \sigma$ versus $\log \tau$ along with the associated confidence in the $\sigma$. For small batches of data a desk calculator could be used and the computer analysis would not be necessary. An example of a specific Allan variance computation is shown in Appendix C. A typical plot of $\log \sigma$ versus $\log \tau$ is shown in figure 8. The dashed lines indicate the slopes which are characteristic of the types of noise indicated.

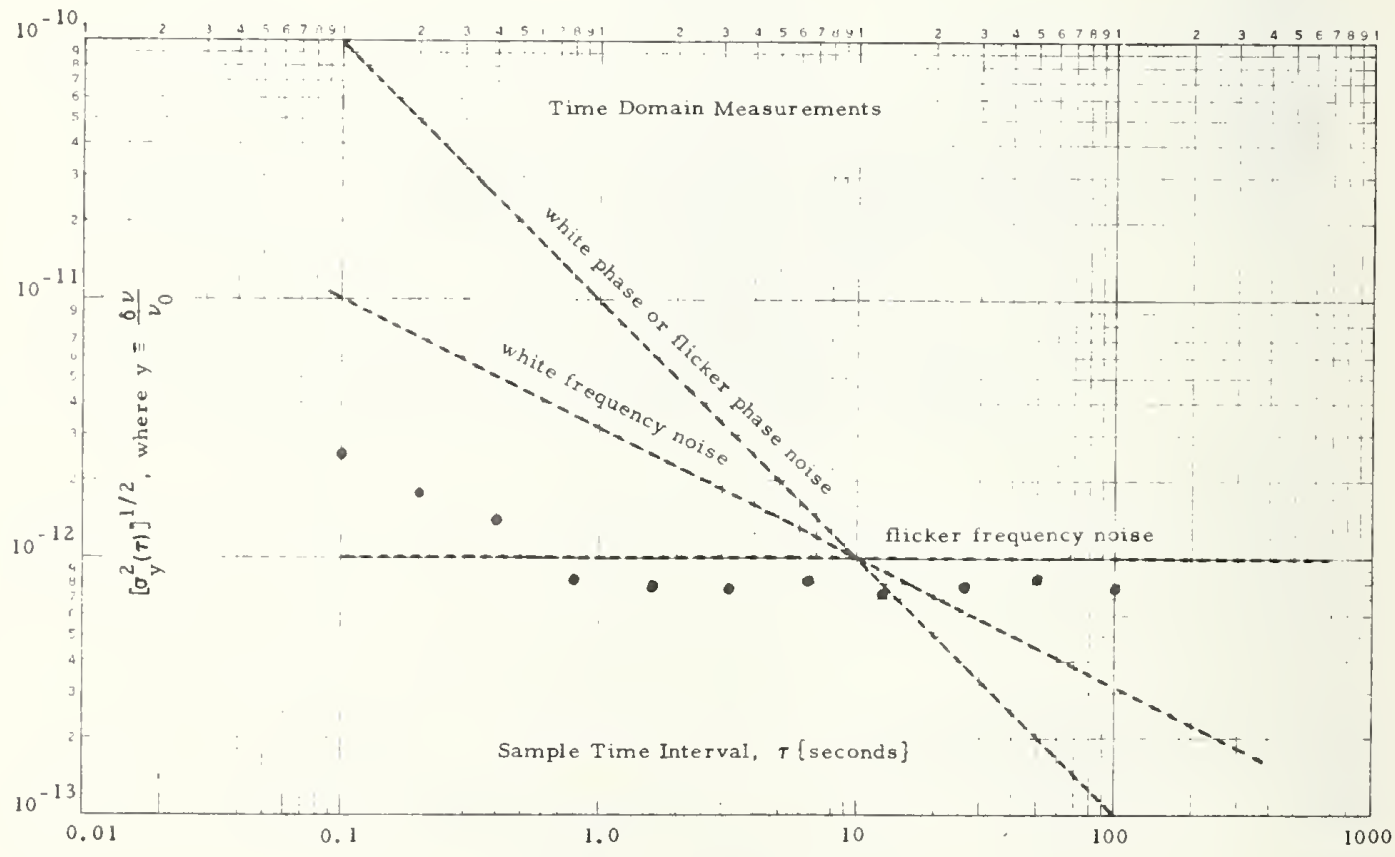

FIGURE 8: SIGMA VERSUS TAU 
An additional useful system illustrated in figure 9 is used for differential phase noise measurements of various discrete components which are frequently used in stability measurement systems. In this system only one frequency source is used. Its output is split so that part of the signal passes through the component to be tested.

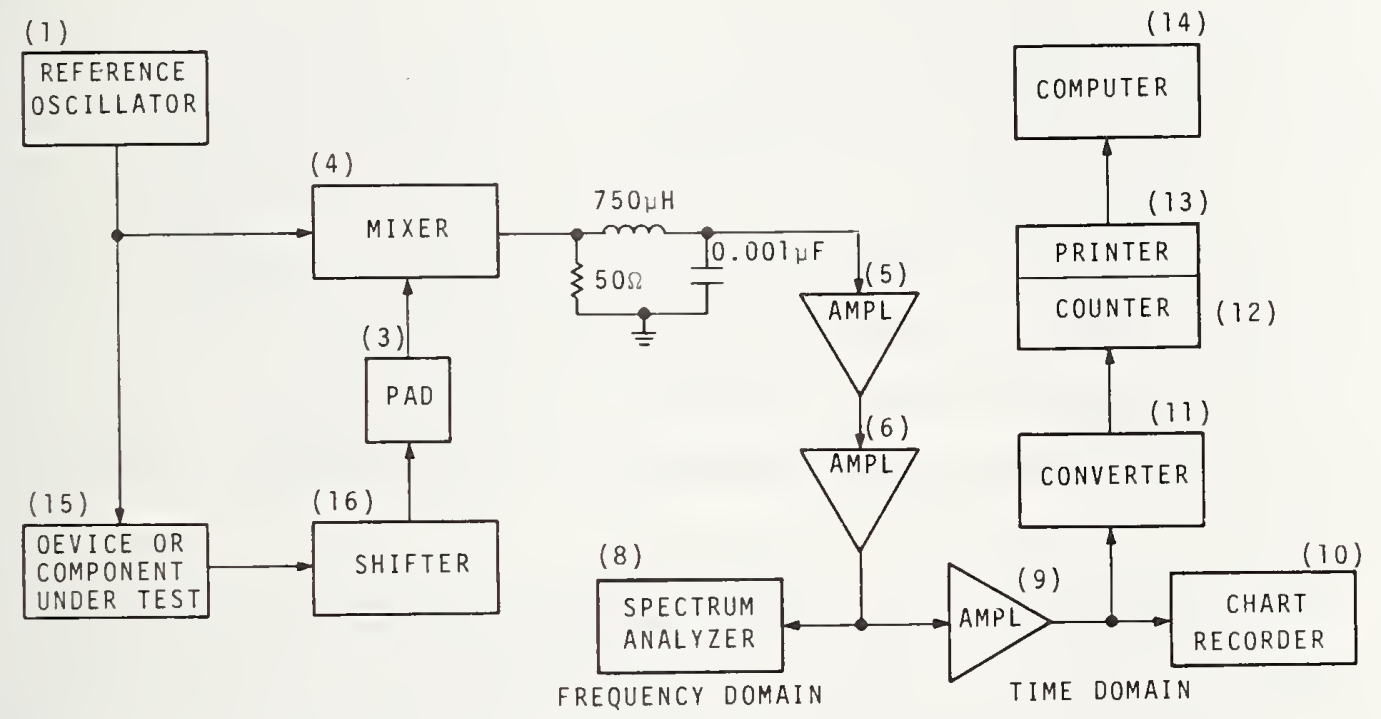

FIGURE 9: DIFFERENTIAL PHASE NOISE I'EASUREMENT

ITEMS (1) THROUGH (14) SAME AS FIGURES 1 ANO 7

(15) ANY OEVICE OR COMPONENT UPON WHICH NOISE MEASUREMENTS ARE DESIRED

(AMPLIFIERS, FILTERS, CAPACITORS, CABLES, PADS, ETC.)

(16) NBS ADJUSTABLE PHASE SHIFTER, 5 MHZ (SEE FIGURE 10)

The signal is adjusted via a phase shifter (fig. 10) so that it is in phase quadrature with the other part of the original signal and is downconverted in the Schottky barrier diode mixer as described in previous

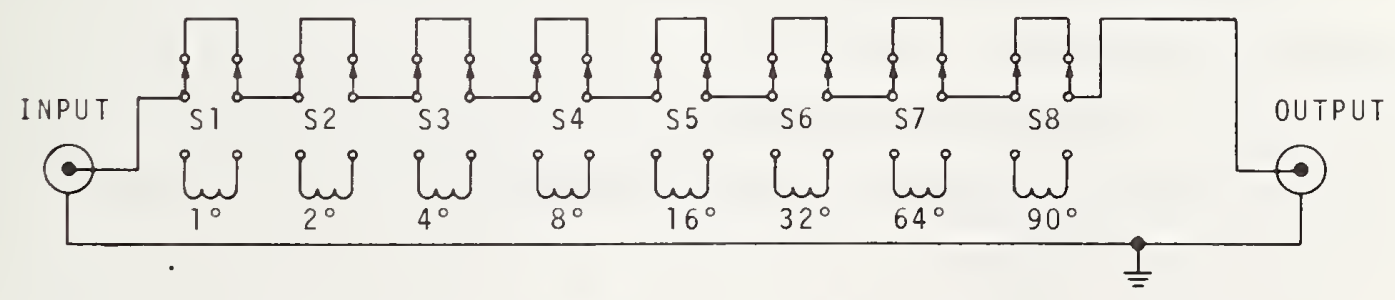

FIGURE 10: AUJUSTABLE PHASE SHIFTER (5MHZ DELAY LINE)

RG174/U CABLE WAS USED FOR EACH SEGMENT OF PHASE SHIFT

CALCULATED AT $\sim 10 \mathrm{~cm}$ PER DEGREE AT $5 \mathrm{MHZ}$. 
systems. A low-pass filter is included before the signal is amplified in special low-noise, low-level dc amplifiers and observed on the spectrum analyzer. Script $\mathscr{L}(\mathrm{f})$ values are calculated at various frequency values, $f$, and plotted. A sample calculation is shown in Appendix B.

The measurement system noise level (e.g., see fig. 6) is easily evaluated. Using the differential phase noise measurement system shown in figure 9, let the "device under test" be a short length of coaxial cable (which is itself not a source of noise). The small amount of noise observed on the spectrum analyzer represents the system noise, mainly due to the mixer (4) or the first amplifier (5). The calculation of the system noise is then the procedure illustrated in Appendix B.

By the phrase very loose phase lock loop, we mean that the bandwidth of the servo response is small compared to the lowest frequency $f$ at which we wish to measure (i.e., the response time is very slow). By the phrase very tight phase lock loop, we mean that the bandwidth of the servo response is relatively large (i.e., the response time is much smaller than the smallest time interval $\tau$ at which we wish to measure).

A convenient chart for translating between frequency domain and time domain is given in Appendix D.

Appendix E lists several important references for measurement of frequency stability. In addition to several general references a number of specific papers are given. These may be useful for better understanding of the problems and principles involved in frequency stability measurements.

An extensive bibliography is given. It includes all references listed elsewhere in the paper. 


\section{MEASUREMENTS OF FREQUENCY STABILITY}

\section{AT MICROWAVE FREQUENCIES}

All of the systems described above have been used extensively for determining frequency stability of 1 to $100 \mathrm{MHz}$ sources. It is in that frequency range, principally, that the most stable, spectrally pure signal sources have been available. However, the measurement systems as described above are not limited to that range. Measurements can be performed readily on sources in the range $0.2 \mathrm{MHz}$ to $500 \mathrm{MHz}$ using the identical systems illustrated in figures 1 and 7 . (For the system in fig. 9 the only component which would be different is the phase shifter which must be one capable of functioning at the source frequency.) Similar measurement systems can be used in frequency ranges up to $12 \mathrm{GHz}$ without employing waveguide mixers or other waveguide components. A wider range mixer (instead of the one specified) must be substituted and possibly some isolation of the sources would be needed. Several commercial double-balanced mixers with coaxial connectors are available using Schottky barrier diodes [9]. The techniques of measurement are basically the same as described previously. In general, waveguide components may be used for these frequency stability or phase noise measurements between $5 \mathrm{GHz}$ and 12. $4 \mathrm{GHz}$ (and higher). Balanced mixers can be made using a $180^{\circ}$ hybrid (magic tee) as the coupling. device with two diodes mounted either in series or in shunt with the output. Our interest (or experience) in this frequency range has not been extensive partly because of the lack of spectrally pure sources at higher frequencies. However, the measurements which have been made employ the previously described techniques primarily. 
The results of our measurements indicate that the precision capabilities are better than what is necessary for determining stability on the relatively noisy sources available (i.e., klystrons, Gunn oscillators, sources derived from lower frequency by multiplication, etc.).

\section{SUMMARY}

Concise definitions for specifying frequency stability have been given for measurements in the frequency domain and time domain. The attempt is to be basic so that a person without extensive knowledge in the field can quickly grasp the concepts involved (extended derivations and theory are left to the appendices or references). Several contemporary measurement techniques are reviewed and compared. Operational systems for measurement of frequency stability are described in detail sufficient to facilitate duplication of the apparatus used. Uniform methods of reporting data and techniques of measurement are recommended as advantageous and desirable so that better interpretation of specifications for frequency stability can be accomplished. The measurement systems and techniques may be utilized well into the microwave region.

The author is particularly indebted to Dr. Donald Halford for his valuable assistance and comments in the preparation of this document. 


\section{REFERENCES}

[1] J. A. Barnes, A. R. Chi, L. S. Cutler, et al., "Characterization of Frequency Stability, "NBS Technical Note 394 (October 1970); also published in IEEE Trans. on Instr. and Meas. IM-20, No. 2, pp. 105-120 (May 1971).

[2] D. W. Allan, "Statistics of Atomic Frequency Standards, "Proc. IEEE 54, No. 2, pp. 221-230 (February 1966).

[3] Hewlett-Packard, "Precision Frequency Measurements," Application Note 116 (July 1969).

[4] Hewlett-Packard, "Computing Counter Applications Library," Nos. 7, 22, 27, 29 (1970).

[5] V. Van Duzer, "Short-Term Stability Measurements," Proc. of the IEEE-NASA Symposium on the Definition and Measurement of Short-Term Frequency Stability, NASA SP-80, pp. 269-272 (1965).

[6] D. G. Meyer, "A Test Set for Measurement of Phase Noise on High Quality Signal Sources, "IEEE Trans. on Instr。and Meas. IM-19, No. 4, pp. $215-227$ (November 1970).

[7] R. B. Shields, "Review of the Specification and Measurement of Short-Term Stability, "Microwave Journal, pp. 49-55 (June 1969).

[8] L. S. Cutler and C. L. Searle, "Some Aspects of the Theory and Measurement of Frequency Fluctuations in Frequency Standards, " Proc. IEEE 54, No. 2, pp. $136-154$ (February 1966).

[9] G. R. Reeve, "Signal Detection Systems, " NBS Report 9767 (October 1967), sponsored by Army/Navy/Air Force JTCG-METCAL/CCG on Contract 69-25b. 


\section{Glossary of Symbols}

\section{$\nu$}

vo

$\delta \nu$

v

$x$

$\bar{y}$

$f_{h}$

$S_{y}(f)$

$s_{\delta V}(v)$

$\delta \varnothing$

$S_{\delta \phi^{(f)}}$

$\mathcal{L}(\mathrm{f})$

N

M

Carrier frequency

Fourier frequency of fluctuations

Nominal frequency of source

Frequency fluctuation

Fractional frequency fluctuations, $\frac{\delta \nu}{i}$

Time interval fluctuations, $\frac{\mathrm{d} x}{\mathrm{dt}} \equiv y$

Average of y over a time interval $T$

Defined as B, high frequency cutoff (bandwidth)

Spectral density of $y$

Radio frequency power spectral density

Phase fluctuation

Spectral density of phase fluctuations; $S_{\delta \phi}(f)=S_{y}(f) \frac{\nu_{0}^{2}}{f^{2}}$

Frequency domain measure of phase fluctuations;

Script $\mathcal{L}(f)$ is defined as the ratio of

$\frac{\text { Power density (one phase modulation sideband) }}{\text { Power (total signal) }}$

For small $\delta \notin, \mathrm{S}_{\delta \phi}(\mathrm{f})=2 \mathcal{L}(\mathrm{f})$

Number of data values used in obtaining a sample variance

Total number of data values available (usually $M \gg N$ )

Time interval between the beginnings of two successive measurements 


\section{APPENDIX A cont.}

$\tau$

$r$

t

$\sigma_{\mathrm{y}}^{2}(\mathrm{~N}, \mathrm{~T}, \tau)$ and repeated every $\mathrm{T}$ units of time (Allan variance)

$\mathrm{k}, \mathrm{n}$

Intigers (used as index of summation)

$\sigma_{y}^{2}(\tau)$

$\sigma$

$A_{\text {ptp }}$

rms

Sampling time interval

Parameter related to dead time; $\mathrm{r} \equiv \mathrm{T} / \tau$

Time variable

Specific Allan variance where $N=2, T=T$

Square root of a variance

Peak-to-peak voltage of a beat frequency at output of mixer

Root-mean-square (noise) voltage at output of mixer as measured by a spectrum analyzer 


\section{A Sample Calculation of Script 2}

For convenience of computation and plotting it often is advantageous to set the beat frequency voltage (before locking) to $\frac{1}{\sqrt{10}}$ volts $(0.316 \mathrm{~V})$ peak-to-peak at the mixer output. Then (after lock) with the output of the phase detector expressed in rms nanovolts per root hertz, direct plotting is facilitated for $\mathcal{L}(f)$ in decibels versus frequency in hertz. In this case 1000, 100, and 10 nanovolts per root hertz correspond to $-110,-130$, and $-150 \mathrm{~dB}$ respectively. A sample calculation demonstrating this convenience is shown below.

Given:

$$
\begin{aligned}
& \left.A_{\text {ptp }}=0.316 \mathrm{~V} \text { (i.e., } \frac{1}{\sqrt{10}} \mathrm{~V}\right) \\
& \mathrm{v}_{\mathrm{rms}}=100 \mathrm{nV} \mathrm{Hz}^{-1 / 2} @ \mathrm{f}=20 \mathrm{~Hz}
\end{aligned}
$$

$$
\begin{aligned}
& \mathcal{L}(20 \mathrm{~Hz})=\left(\frac{\mathrm{v}_{\mathrm{rms}}}{\mathrm{A}_{\mathrm{ptp}}}\right)^{2}=\left(\frac{100 \mathrm{nV} \mathrm{Hz}}{-1 / 2}\right)^{2}=\left(\frac{10^{-7}}{\sqrt{10^{-1}}}\right)^{2} \mathrm{~Hz}^{-1}=\frac{10^{-14}}{10^{-1}} \mathrm{~Hz}^{-1} \\
& =10^{-13} \mathrm{~Hz}^{-1}=-130 \mathrm{~dB}
\end{aligned}
$$

or using logarithms:

$$
\begin{aligned}
\mathscr{L}^{(20 \mathrm{~Hz})=} 20 \log _{10}\left(\frac{\mathrm{V}}{\mathrm{rms}} \mathrm{A}_{\mathrm{ptp}}\right. & =20 \log _{10} \frac{\left(10^{-7} \mathrm{~V} \cdot \mathrm{Hz}^{-1 / 2}\right)}{\left(10^{-1 / 2} \mathrm{~V}\right)}=20(-7+\mathrm{C} .5) \\
& =-130 \mathrm{~dB}
\end{aligned}
$$

If the phase noise follows flicker law, at $\mathrm{f}=1 \mathrm{~Hz}$ it is 20 times worse (or $13 \mathrm{~dB}$ greater), that is

$$
\mathscr{L}(1 \mathrm{~Hz})=-130 \mathrm{~dB}+13 \mathrm{~dB}=-117 \mathrm{~dB} .
$$


A Sample Calculation of Allan Variance, $\sigma_{y}^{2} \underline{(\tau)}$

$\sigma_{y}^{2}(\tau) \equiv\left\langle\sigma_{y}^{2}(N=2, T=\tau, \tau)\right\rangle=\left\langle\frac{\left(\bar{y}_{k+1}-\bar{y}_{k}\right)^{2}}{2}\right\rangle \approx \frac{1}{2(M-1)} \sum_{k=1}^{M-1}\left(\bar{y}_{k+1}-\bar{y}_{k}\right)^{2}$

in the example below:

Number of data values available, $M=9$

Number of differences averaged, $M-1=8$

Sampling time interval $\tau=1 \mathrm{~s}$

Data values First differences

(y) $\quad\left(\bar{y}_{k+1}-\bar{y}_{k}\right)$

892

809

823

798

671

644

883

903

677
$-83$ 14

$-25$

$-127$

-27
$-\quad 239$

239

20

$-226$
First differences squared $\left(\bar{y}_{k+1}-\bar{y}_{k}\right)^{2}$

6889

196

625

16129

729

57121

400

51076

\section{M - 1}

$$
\sum_{k=1}\left(\bar{y}_{k+1}-\bar{y}_{k}\right)^{2}=133165
$$

Based on these data:

$$
\begin{aligned}
& \sigma_{y}^{2}(\tau)=\frac{133165}{2(8)}=8322.81, \\
& {\left[\sigma_{y}^{2}(\tau)\right]^{1 / 2}=\sqrt{8322.81}=91.23, N=2, T=\tau=1 \mathrm{~s} .}
\end{aligned}
$$

In this example, the data values may be understood to be expressed in parts in $10^{12}$. 
Using the same data as in the above example it is possible to calculate the Allan variance for $T=2 \mathrm{~s}$ by averaging pairs of adjacent data values and using these averaged values as new data values to proceed with the calculation as before. Allan variance values may be obtained for $T=3 \mathrm{~s}$ by averaging three adjacent data values in a similar manner, etc., for larger values of $\tau$.

Ideally the calculation is done via a computer and a large number, $M$, of data values should be used. (Typically $M=256$ data values are used in the NBS computer program.) The statistical confidence of the calculated Allan variance improves nominally as the square root of the number, $M$, of datavalues used. For $M=256$, the confidence of the Allan variance is not expected to be better than approximately $\frac{1}{\sqrt{256}} \times 100 \% \approx 7 \%$ in the rms sense. The use of $M \gg 1$ is logically similar to the use of $\mathrm{B}_{\mathrm{a}} \cdot \tau_{\mathrm{a}} \gg 1$ in spectrum analysis measurements, where $B_{a}$ is the analysis bandwidth (frequency window) of the spectrum analyzer, and $\tau_{a}$ is the post-detection averaging time of the spectrum analyzer. 
APPENDIX D

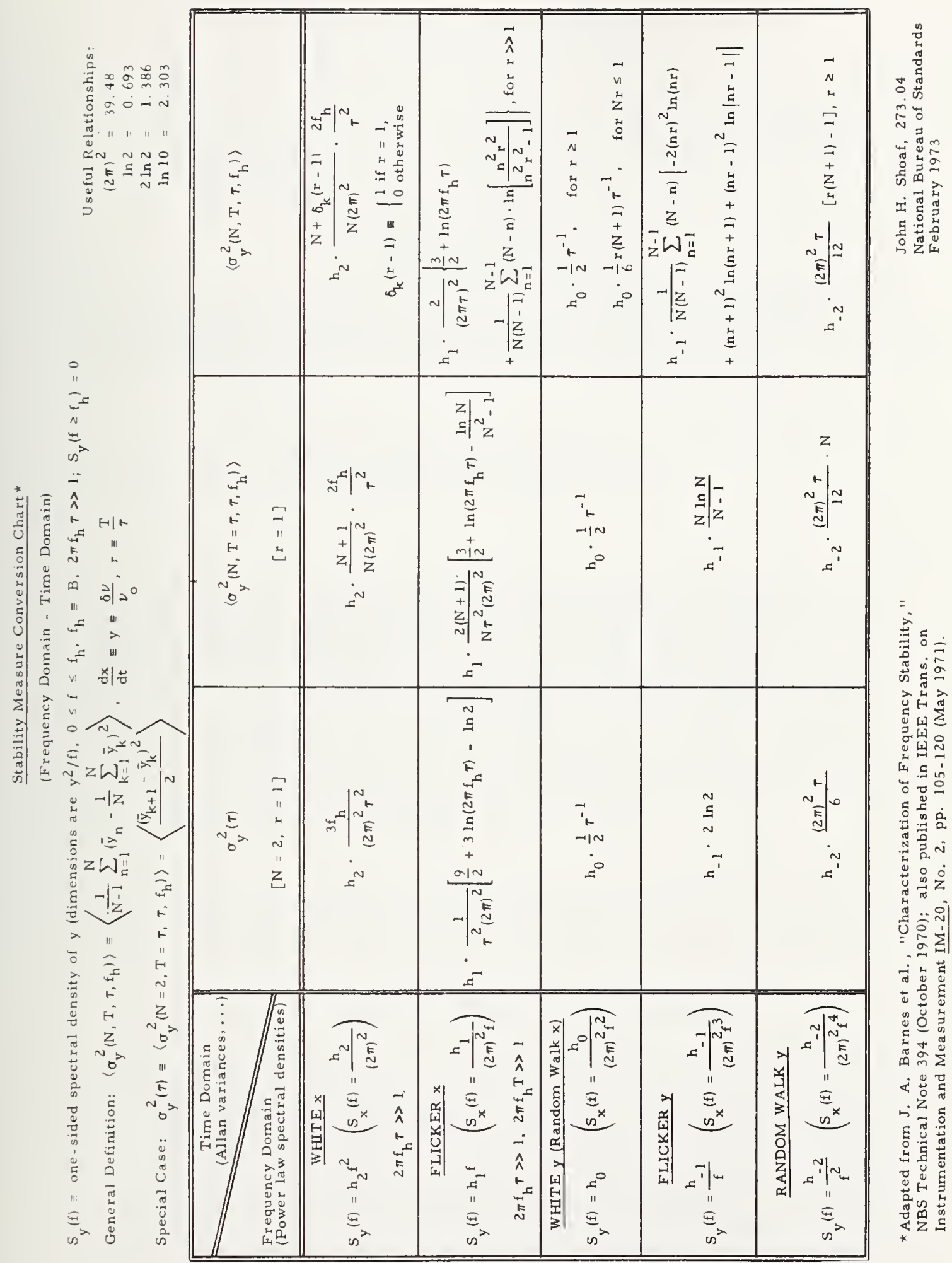




\section{APPENDIX E}

$\underline{\text { Some Important References }}$

for

Measurement and Specification of Frequency Stability

\section{General References}

1. November or December of even-numbered years IEEE

Transactions on Instrumentation and Measurement (Conference

on Precision Electromagnetic Measurements, held every 2 years).

2. February 1966 Proceedings of the IEEE, special is sue on frequency stability (IEEE-NASA Symposium).

3. Proceedings of the IEEE-NASA Symposium on the Definition and Measurement of Short-Term Frequency Stability at

Goddard Space Flight Center, Greenbelt, Maryland,

November 23-24, 1964. Prepared by Goddard Space Flight

Center (Scientific \& Technical Information Division, National

Aeronautics and Space Administration, Washington, D. C. ,

1965). Copies available for $\$ 1.75$ from the U. S. Government

Printing Office, Washington, D.C. 20402.

4. The annual proceedings of the Symposium on Frequency Control (Ft. Monmouth). These papers are not edited nor reviewed.

5. J. A. Barnes, A. R. Chi, L. S. Cutler, et al., "Characterization of Frequency Stability, "NBS Technical Note 394 (October 9970); also published in IEEE Trans. on Instr. and Meas. IM-20, No. 2, pp. 105-120 (May 1971). This is the most definitive discussion to date of the characterization and measurement of frequency stability. It was prepared by the Subcommittee on Frequency Stability of the Institute of Electrical and Electronic Engineers. 


\section{Some Specific Papers}

6. D. W. Allan, "Statistics of Atomic Frequency Standards," Proc. IEEE, vol. 54, pp. 221-230, February 1966. A thorough understanding of this paper is important for everyone who wishes to measure and quote performance of frequency standards in the time domain, e. g., $\sigma$ versus $\tau$ plots. The data analysis must take into account the number of samples taken and how they are used.

7. David W. Allan, B. E. Blair, D. D. Davis, and H. E. Machlan, "Precision and Accuracy of Remote Synchronization via Portable Clocks, Loran C, and Network Television Broadcasts," Proc. 25th Annual Symposium on Frequency Control, Fort Monmouth, N.J., 26-28 April 1971, to be published.

8. E. J. Baghdady, R. N. Lincoln, and B. D. Nelin, "ShortTerm Frequency Stability: Characterization, Theory, and Measurement," Proc. IEEE, vol. 53, pp. 704-722, July 1965. Among many other topics, the possible problem of AM noise is discussed.

9. Helmut Brandenberger, Frederic Hadorn, Donald Halford, and John H. Shoaf, "High Quality Quartz Crystal Oscillators: Frequency Domain and Time Domain Stability," Proc. 25th Annual Symposium on Frequency Control, Fort Monmouth, N.J., 26-28 April 1971, to be published. An example of 1970 "state-of-the-art" measurements.

10. L. S. Cutler, "Present Status in Short Term Frequency Stability, "Frequency, vol. 5, pp. 13-15, SeptemberOctober 1967. This is a well-written, concise progress report with indications for future effort. Caution: His examples I and II were not in fact state-of-the-art, while example IV has some factor-of-ten typographical errors as given。 
11. L. S. Cutler and C. L. Searle, "Some Aspects of the Theory and Measurement of Frequency Fluctuations in Frequency Standards," Proc. IEEE, vol. 54, pp. 136-154, February 1966. This is a useful treatment of some of the theory, mathematics, and measurement techniques--with physical insight into the noise processes of practical concern.

12. W. A. Edson, "Noise in Oscillators," Proc. IRE, vol. 48, pp. 1452-1466, August 1960. This paper is an "old classic."

13. C. Finnie, R. Sydnor, and A. Sward, "Hydrogen Maser Frequency Standard, "Proc. 25th Annual Symposium on Frequency Control, Fort Monmouth, N. J., 26-28 April 1971 , to be published.

14. D. J. Glaze, "Improvements in Atomic Beam Frequency Standards at the National Bureau of Standards, "IEEE Trans. on Instr. and Meas. IM-19, No. 3, pp. 156-160, August 1970.

15. D. B. Leeson, "A Simple Model of Feedback Oscillator Noise Spectrum," Proc. IEEE (Letters), vol. 54, pp. 329 330, February 1966. Descriptive, in a simple, practical manner.

16. J. A. Mullen, "Background Noise in Nonlinear Oscillators," Proc. IRE, vol. 48, pp. 1467-1473, August 1960. An "old classic."

17. H. P. Stratemeyer, "The Stability of Standard-Frequency Oscillators," General Radio Experimenter, vol. 38, pp. 1-16, June 1964. Easy reading.

18. V. Van Duzer, "Short-Term Stability Measurements," IEEE-NASA Symposium on Short-Term Frequency Stability, Washington, D.C.: U. S. Government Printing Office, pp. 269-272, NASA-SP80. The basic method described by Van Duzer is simple, elegant, easily instrumented, easily modified, extremely versatile, and capable of the best resolution which is attained at today's state-of-the-art. 
1. D. W. Allan, "Statistics of Atomic Frequency Standards, "Proc. IEEE, vol. 54, pp. 221-230, February 1966.

2. David W. Allan, B. E. Blair, D. D. Davis, and H. E. Machlan, "Precision and Accuracy of Remote Synchronization via Portable Clocks, Loran C, and Network Television Broadcasts," Proc. 25 th Annual Symposium on Frequency Control, Fort Monmouth, N.J., 26-28 April 1971, to be published.

3. A. E. Anderson and H. P. Brower, "A Tunable Phase Detector for Short-Term Frequency Measurement," Proc. IEEE-NASA Symposium on the Definition and Measurement of Short-Term Frequency Stability, NASA SP-80, pp. 295-302, 1965.

4. J. R. Ashley and C. B. Searles, "Microwave Oscillator Noise Reduction by a Transmission Stabilizing Cavity, "IEEE Trans. on Microwave Theory and Techniques MTT-16, pp. 743-748, September 1968.

5. J. R. Ashley, C. B. Searles, and F. M. Palka, "The Measurement of Oscillator Noise at Microwave Frequencies," IEEE Trans. on Mic rowave Theory and Techniques MTT-16, pp. 753-760, September 1968.

6. W. Atkinson and L. Fey, "Statistical Aspects of Clock Errors," NBS Report 6085, January 5, 1960.

7. W. R. Atkinson, L. Fey, and J. Newman, "Spectrum Analysis of Extremely Low Frequency Variations of Quartz Oscillators, " Proc. IEEE (Correspondence), vol. 51, p. 379, February 1963.

8. E. J. Baghdady, R. D. Lincoln, and B. D. Nelin, "Short-Term Frequency Stability: Theory, Measurement, and Status," Proc. IEEE-NASA Symposium on Short-Term Frequency Stability, NASA SP-80, pp. $65-87,1965$; also Proc. IEEE, vol. 53, pp. 704-722, $2110-2111,1965$.

9. J. J. Bagnall, Jr., "The Effect of Noise on an Oscillator Controlled by a Primary Reference, "NEREM 1959 Record, pp. $84-86$. 
10. J. A. Barnes, "Studies of Frequency Stability, "Unpublished NBS Report, August 15, 1969.

11. J. A. Barnes, "Frequency Measurement Errors of Passive Resonators Caused by Frequency-Modulated Exciting Signals," IEEE Trans. on Instrumentation and Measurement IM-19, No. 3, pp. 147-152, August 1970.

12. J. A. Barnes, "Atomic Timekeeping and the Statistics of Precision Signal Generators, "Proc. IEEE, vol. 54, pp. 207-220, February 1966.

13. J. A. Barnes, "Tables of Bias Functions, $B_{1}$ and $B_{2}$, for Variances Based on Finite Samples of Processes with Power Law Spectral Densities," NBS Technical Note 375, January 1969.

14. J. A. Barnes and D. W. Allan, "A Statistical Model of Flicker Noise," Proc. IEEE, vol. 54, pp. 176-178, February 1966.

15. J. A. Barnes and D. W. Allan, "Effects of Long-Term Stability on the Definition and Measurement of Short-Term Stability, " Proc. IEEE-NASA Symposium on Short-Term Frequency Stability, NASA SP-80, pp. $119-123,1965$.

16. J. A. Barnes, A. R. Chi, L. S. Cutler, et al., "Characterization of Frequency Stability, " NBS Technical Note 394, October 1970; also published in IEEE Trans. on Instrumentation and Measurement IM-20, No. 2, pp. 105-120, May 1971.

17. J. A. Barnes and L. E. Heim, "A High-Resolution Ammonia Maser Spectrum Analyzer," IRE Trans. on Instrumentation I- 10. No. 1, pp. 4-8, June 1961 .

18. J. A. Barnes and R. C. Mockler, "The Power Spectrum and Its Importance in Precise Frequency Measurements, "IRE Trans. on Instrumentation I-9, pp. 149-155, September 1960.

19. J. S. Bendat, Principles and Applicatiuns of Random Noise Theory. New York: John Wiley and Sons, p. 79, 1958. 
20. W. R. Bennett, Electrical Noise. New York: McGrav/-Hill, 1960.

21. W. R. Bennett, "Methods of Solving Noise Problems, "Proc. IRE, vol. 44, pp. $609-638$ (Eq. 223 ff.), May 1956.

22. I. Berstein and G. Gorelik, "Frequency Modulation Noise in Oscillators, "Proc. IRE (Correspondence), vol. 45, p. 94 , January 1957.

23. C. Bingham, M. D. Godfrey, and J. W. Tukey, "Modern Techniques of Power Spectrum Estimation, "IEEE Trans. AU, vol. 15, pp. 56-66, June 1967.

24. R. B. Blackman and J. W. Tukey, The Measurement of Power Spectra. New York: Dover, 1958.

25. Helmut Brandenberger, Frederic Hadorn, Donald Halford, and John H. Shoaf, "High Quality Quartz Crystal Oscillators:

Frequency Domain and Time Domain Stability, "Proc. 25th Annual Symposium on Frequency Control, Fort Monmouth, N.J., 26-28 April 1971, to be published.

26. E. O. Brigham and R. E. Morrow, "The Fast Fourier Transform," IEEE Spectrum, vol. 4, pp. 63-70, December 1967.

27. J. R. Buck and D. J. Healey, III, "Calibration of Short-Term Frequency Stability Measuring Apparatus," Proc. IEEF. L. , vol. 54, p. 305, February 1966.

28. J. R. Buck and D. J. Healey, III, "Short Term Frequency Stability Measurement of Crystal Controlled X-Band Source, "Proc. IEEE-NASA Symposium on Short-Term Frequency Stability, NASA SP-80, pp. 201-209, 1965.

29. J. R. Buck, D. J. Healey, III, and M. Meiseles, "Measurement of Phase Stability of Quartz Crystal Oscillators for Airborne Radar Applications," IEEE International Conv. Rec., pt. 8, pp. 34-42, March 1964. 
30. G. A. Campbell and R. M. Foster, Fourier Integrals for Practical Applications. Princeton, N.J.: D. Van Nostrand, 1948.

31. R. A. Campbell, "Stability Measurement Techniques in the Frequency Domain, "Proc. IEEE-NASA Symposium on the Definition and Measurement of Short-Term Frequency Stability, NASA SP-80, pp. 231-235, 1965.

32. E. R. Chenette, "Low Noise Trailsistor Amplifiers," Solid State Design, vol. 5, pp. 27-30, February 1964.

33. J. Chramiec, "Noise Properties of a Superregenerative Parametric Amplifier, "Proc IEEE, vol. 54, p. 704, April 1966.

34. E. L. Crow, "The Statistical Construction of a Single Standard from Several Available Standards, "IEEE Trans. on Instrumentation and Measurement IM-13, pp. 180-185, December 1964.

35. L. S. Cutler, "Some Aspects of the Theory and Measurement of Frequency Fluctuations in Frequency Standards," Proc. IEEE-NASA Symposium on the Definition and Measurement of Short-Term Frequency Stability, NASA SP-80, pp. 89-100, 1965.

36. L. S. Cutler, "Present Status in Short Term Frequency Stability," Frequency, vol. 5, pp. 13-15, September-October 1967.

37. L. S. Cutler and C. L. Searle, "Some Aspects of the Theory and Measurement of Frequency Fluctuations in Frequency Standards," Proc. IEEE, vol. 54, pp. 136-154, February 1966.

38. W. B. Davenport and W. L. Root, Random Signals and Noise. New York: McGraw Hill, Ch. 6, 1958.

39. E. V. Dvornikov, E. A. Māvrin, and N. V. Morkovin, "A HighStability Transistorized Crystal Oscillator, "Pribory i Tekhn. Eksperim. (USSR), No. 4, July-August 1963. For English translation see Instr. Exper. Tech. (USSR), pp. 672-674, JulyAugust 1963.

40. W. A. Edson, "Noise in Oscillators," Proc. IRE, vol. 48, pp. 1454-1466, August 1960. 
41. W. A. Edson, "Progress and Problems in Short Term Stability," Proc. 19th Annual Symposium on Frequency Control, Fort Monmouth, N.J., pp. 43-48, 20-22 April 1965.

42. R, Esposito and J. A. Mullen, "Noise in Oscillators with General Tank Circuits," IRE International Conf. Rec., pt. 4, pp. 202-208, March 1961.

43. C. Finnie, R. Sydnor, and A. Sward, "Hydrogen Maser Frequency Standard," Proc. 25th Annual Symposium on Frequency Control, Fort Monmouth, N.J., 26-28 April 1971, to be published.

44. L. Fey, W. R. Atkinson, and J. Newman, "Obscurities of Oscillator Noise," Proc. IEEE (Correspondence), vol. 52, pp. 104-105, January 1964.

45. E. A. Gerber and R. A. Sykes, "State of the Art--Quartz Crystal Units and Oscillators," Proc. IEEE, vol. 54, pp. 103-116, February 1966.

46. E. A. Gerber and R. A. Sykes, "Quartz Frequency Standards," Proc. IEEE, vol. 55, pp. 783-791, June 1967.

47. D. J. Glaze, "Improvements in Atomic Beam Frequency Standards at the National Bureau of Standards, "IEEE Trans. on Instrumentation and Measurement IM-19, No. 3, pp. 156-160, August 1970.

48. M.J.E. Golay, "Monochromaticity and Noise in a Regenerative Electrical Oscillator," Proc. IRE, vol. 48, pp. 1473-1477, August 1960.

4C. C. H. Grauling, Jr. and D. J. Healey, Ш, "Instrumentation for Measurement of the Short-Term Frequency Stability of Microwave Sources," Proc. IEEE, vol. 54, pp. 249-257, February 1966.

50. P. Grivet and A. Blaquière, "Nonlinear Effects of Noise in Electronic Clocks," Proc. IEEE, vol. 51, pp. 1606-1614, November 1963. 
51. J. D. Hadad, "Basic Relation Between the Frequency Stability Specification and the Application," Proc. IEEE-NASA Symposium on the Definition and Measurement of Short-Term Frequency Stability, NASA SP-80, pp. 11-18, 1965.

52. E. Hafner, "The Effects of Noise on Crystal' Oscillators, "Proc. IEEE, p. 179, February 1966.

53. Donald Halford, "A General Mechanical Model for $|f|^{\alpha}$ Spectral Density Random Noise with Special Reference to Flicker Noise l|f|," Proc. IEEE, vol. 56, No. 2, pp. $251-258$, March 1968.

54. Donald Halford, A. E. Wainwright, and James A. Barnes, "Flicker Noise of Phase in RF Amplifiers and Frequency Multipliers: Characterization, Cause, and Cure," (Summary) Proc. 22nd Annual Symposium on Frequency Control, Fort Monmouth, N.J., pp. 340-341, April 1968.

55. Hewlett-Packard, "Frequency and Time Standards," Application Note 52, 1965.

56. Hewlett-Packard, "Precision Frequency Measurements," Application Note 116, July 1969.

57. Hewlett-Packard, "Computing Counter Applications Library," Nos. 7, 22, 27, 29; 1970 .

58. R. H. Holman and L. J. Paciorek, "Short-Term Stability Measurement Techniques and Results," Proc. IEEE-NASA Symposium on the Definition and Measurement of Short-Term Frequency Stability, NASA SP-80, pp. 237-252, 1965.

59. S. L. Johnson, B. H. Smith, and D. A. Calder, "Noise Spectrum Characteristics of Low-Noise Microwave Tubes and Solid-State Devices," Proc. IEEE, vol. 54, pp. 258-265, February 1966.

60. P. Kartasshoff, "Shot-Effect Influence on the Frequency of an Oscillator Locked to an Atomic Beam Resonator, "Proc. IEEE-NASA Symposium on the Definition and Measurement of Short-Term Frequency Stability, NASA SP-80, pp. 303-308, 1965. 
61. R. F. Lacey, A. L. Helgesson, and J. H. Holloway, "Short-Term Stability of Passive Atomic Frequency Standards," Proc. IEEE, vol. 54, pp. 170-176, February 1966.

62. R. W. Larson, "Power Spectrum of Oscillator and Frequency Multiplier Phase Jitter," Proc. IEEE, vol. 54, p. 796, May 1966.

63. D. B. Leeson, "A Simple Model of Feedback Oscillator Noise Spectrum," Proc. IEEE L., vol. 54, pp. 329-330, February 1966.

64. D. B. Leeson and G. F. Johnson, "Short-Term Stability for a Doppler Radar: Requirements, Measurements, and Techniques," Proc. IEEE, vol. 54, pp. 244-248, February 1966.

65. R. M. Lerner, "The Effects of Noise on the Frequency Stability of a Linear Oscillator," Proc. Natl. Electr. Conf., vol. 7, pp. $275-280,1951$.

66. L. Malling, "Phase-Stable Oscillators for Space Communications, including the Relationship between the Phase Noise, the Spectrum, the Short-Term Stability, and the $Q$ of the Oscillator, "Proc. IRE, vol. 50, pp. 1656-1664, July 1962 .

67. J. C. McDade, "Measurement of Additive Phase Noise Contributed by the Step-Recovery Diode in a Frequency Multiplier, " Proc. IEEE L., vol. 54, pp. 292-294, February 1966.

68. D. G. Meyer, "A Test Set for Measurement of Phase Noise on High Quality Signal Sources, "IEEE Trans. on Instrumentation and Measurement IM-19, No. 4, pp. 215-227, November 1970.

69. A. H. Morgan and J. A. Barnes, "Short-Time Stability of a Quartz-Crystal Oscillator as Measured with an Ammonia Maser," Proc. IRE (Letter), vol. 47, No. 10, p. 1782, October 1959.

70. J. A. Mullen, "Background Noise in Nonlinear Oscillators," Proc. IRE, vol. 48, pp. 1467-1473, August 1960.

71. J. A. Mullen, "Background Noise in Oscillators with R. F. Pushing," J. Electronics and Control, vol. 10, pp. 127-138, February 1961. 
72. J. G. Ondria, "A Microwave System for Measurements of AM and FM Noise Spectra, "IEEE Trans. on Microwave Theory and Techniques MTT-16, pp. 767-781, September 1968.

73. R. E. Paradysz and W. L. Smith, "Measurement of FM Noise Spectra of Low-Noise VHF Crystal Controlled Oscillators, " IEEE Trans. on Instrumentation and Measurement IM-15, pp. 202 211, December 1966.

74. V. Prabhu, "Noise Performance of Abrupt-Junction Varactor Frequency Multipliers, "Proc. IEEE L., vol. 54, pp. 285-287, February 1966.

75. J. Rarity, L. Saporta, and G. Weiss, "Study of Short Term Stability of Crystal Oscillators, "New York University, New York, N. Y., Tech. Rpt. Cont. DA36-039-SE-87450, DA Project 3A-99-15-02, 02-02.

76. G. R. Reeve, "Signal Detection Systems," NBS Report 9767 , October 1967, sponsored by Army/Navy/Air Force JTCG-METCAL/CCG on Contract 69-25b.

77. C. L. Searle, R. D. Posner, R. S. Badessa, and V. J. Bates, "Computer-Aided Calculation of Frequency," Proc. IEEE-NASA Symposium on the Definition and Measurement of Short-Term Frequency Stability, NASA SP-80, pp. 273-277, November 1964.

78. R. B. Shields, "Review of the Specification and Measurement of Short-Term Stability, "Microwave Journal, pp, 49-55, June 1969.

79. W. L. Smith and W. J. Spencer, "Quartz Crystal Controlled Oscillators," B.T. L., Final Report, Cont. DA 36-039 sc-85373, Dept. of the Army, Proj.3G-26-05-001-01, March 15, 1963.

80. W. J. Spencer and W. L. Smith, "Precision Crystal Frequency Standards," Proc. 15th Annual Symposium on Frequency Control, Fort Monmouth, N.J., pp. 139-155, 1961.

81. J. L. Stewart, "Frequency Modulation Noise in Oscillators," Proc. IRE, vol. 44, pp. 372-376, March 1956. 
82. H. L. Stover, "Theoretical Explanation for the Output Spectra of Unlocked Driven Oscillators," Proc. IEEE L., vol. 54, pp. 310 311 , February 1966.

83. H. P. Stratemeyer, "The Stability of Standard-Frequency Oscillators," General Radio Experimenter, vol. 38, pp. 1-16, June 1964.

84. R. Sydnor, J. J. Caldwell, and B. E. Rose, "Frequency Stability Requirements for Space Communications and Tracking Systems," Proc. IEEE, vol. 54, pp. 231-236, February 1966.

85. R. A. Sykes, W. L. Smith, and W. J. Spencer, "Performance of Precision Quartz-Crystal Controlled Frequency Generators," IRE Trans. on Instrumentation I-11, pp. 243-247, December 1962.

86. V. Troitsky, "Certain Problems of the Theory of Fluctuations in Oscillators. The Influence of Flicker Noise," Izv. Vysshikh Uchebn. Zavedenii, Radiofiz., vol. 1, pp. 20-33, 1958.

87. A. Tykulsky, "Spectral Measurements of Oscillators," Proc. IEEE L., vol. 54, p. 306, February 1966.

88. V. Van Duzer, "Short-Term Stability Measurements," Proc. IEEE-NASA Symposium on the Definition and Measurement of Short-Term Frequency Stability, NASA SP-80, pp. 269-272, 1965.

89. R.F.C. Vessot, L. F. Mueller, and J. Vanier, "A CrossCorrelation Technique for Measuring the Short-Term Properties of Stable Oscillators," Proc. IEEE-NASA Symposium on the Definition and Measurement of Short-Term Frequency Stability, NASA SP-80, pp. $111-118,1965$.

9C. R.F.C. Vessot, L. Mueller, and J. Vanier, "The Specification of Oscillator Characteristics from Measurements made in the Frequency Domain, "Proc. IEEE, p. 199, February 1966.

91. A. L. Whitwell and A. N. Williams, "A Microwave Technique for Determining Noise Spectra at Frequencies Close to the Carrier," Microwave J., vol. 2, pp. 27-32, November 1959. 
NBS. 114A (REV.7.73)

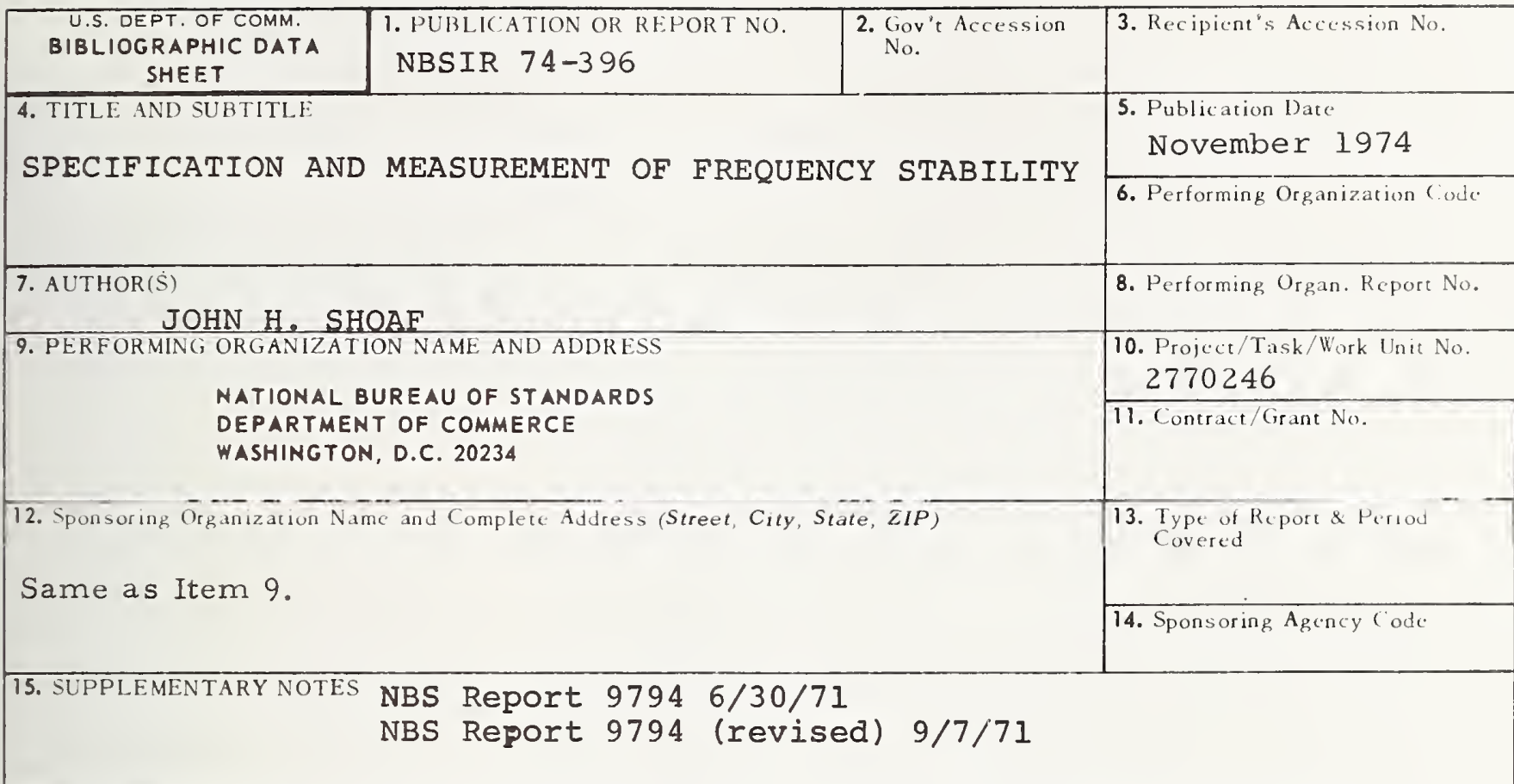

16. ABSTRACT (A 200-word or less factual summary of most significant information. It document includes a significant bibliography or literature survey, mention it here.)

This report gives concise definitions for specifying frequency stability for measurements in the frequency domain and time domain. Standards of terminology and of measurement techniques are recommended. Measurement systems are described in adequate detail so that the apparatus may be duplicated. Proposed extension of the measurement systems through $12.4 \mathrm{GHz}$ is discussed.

17. KEY WORDS (six to twelve entries; alphabetical order; capitalize only the first letter of the first key word unless a proper name; separated by semicolons)

Allan variance, Frequency stability measurements, Measurement system description, Phase noise, Spectral density, Terminology standards.

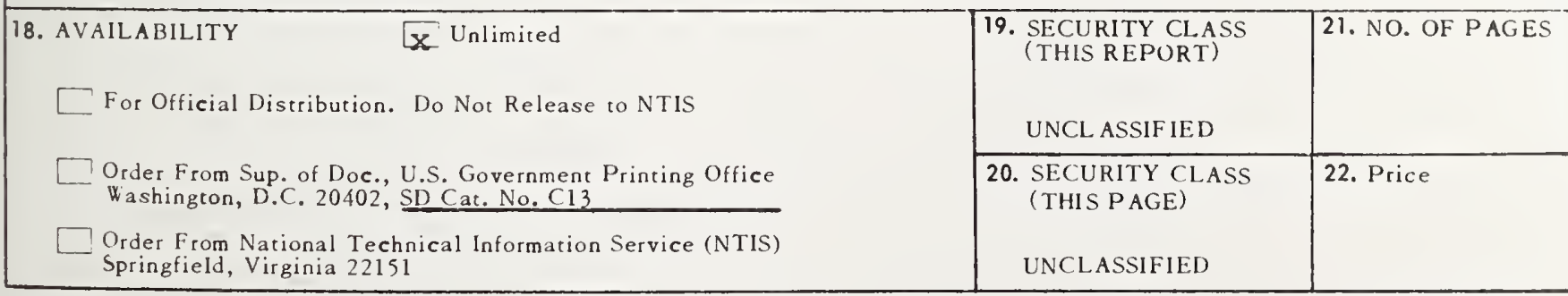


